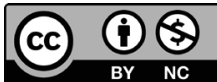

\title{
TRABALHO, DIREITOS INERENTES AO TRABALHO, DIREITO DO TRABALHO E CONSTITUIÇÃO DA REPÚBLICA: O SIGNIFICADO HUMANO, SOCIAL E POLÍTICO DA REFORMA TRABALHISTA
}

WORK, INHERENT RIGHTS TO WORK, LABOR LAW AND CONSTITUTION OF THE REPUBLIC: THE HUMAN, SOCIAL AND POLITICAL SIGNIFICANCE OF THE LABOR REFORM

\author{
Cleber Lucio Almeida \\ Wânia Guimarães Rabêllo Almeida
}

\section{RESUMO}

A pretexto de modernizar o Direito do Trabalho, atrair investimentos estrangeiros e fomentar a competitividade das empresas e, com isso, retomar o crescimento econômico e a criação de empregos, foi realizada, no Brasil, a denominada reforma trabalhista. Este artigo adota como metodologia a revisão bibliográfica e o método dedutivo e define o significado humano, jurídico, social e político da reforma trabalhista, que permite considerá-la um projeto político neoliberal que institui uma nova ordem jurídica, social, econômica e política, contrária àquela definida pela Constituição a partir do lugar que atribui ao trabalho, aos direitos trabalhistas e ao Direito do Trabalho.

Palavras-chave: Reforma trabalhista. Significado humano, social e político. 


\section{ABSTRACT}

Under the pretext of modernizing Labor Law, attracting foreign investment and fostering the competitiveness of companies and, thus, resuming economic growth and job creation, in Brazil, the so-called labor reform was carried out. This article adopts the bibliographic review and the deductive method as methodology and defines the human, legal, social and political meaning of labor reform, which allows it to be considered a neoliberal political project that institutes a new legal, social, economic and political order, contrary to that defined by the Constitution from the place it assigns to work, labor rights and Labor Law.

Keywords: Labor reform. Human, social and political significance.

\section{INTRODUÇÃO}

Os idealizadores e executores da reforma trabalhista a apresentam como indispensável para modernizar o Direito do Trabalho, visando atrair investimentos estrangeiros e fomentar a competitividade das empresas no mercado global e, com isso, retomar o crescimento econômico e a criação de empregos, ao passo, no seu aspecto processual, a apresentam como uma resposta, também indispensável, à má-fé da maior parte dos trabalhadores que comparecem à Justiça do Trabalho e ao ativismo dos tribunais trabalhistas.

Contudo, para compreender a reforma trabalhista é necessário ir além do discurso dos seus defensores. Para esta compreensão, um bom ponto de partida é a análise da relação entre poder e Direito, que constituem faces da mesma moeda, e do alcance das mudanças no trabalho, nos direitos trabalhistas e no Direito do Trabalho, que auxiliam na definição dos seus efeitos humanos, sociais e políticos.

Neste sentido, vale lembrar que: em outubro de 2014, foi reeleita a presidenta Dilma Rousseff; em abril de 2016, a Câmara dos Deputados aprovou a abertura do processo de impeachment contra a presidenta eleita, o que também ocorreu no Senado Federal, em maio de 2016; em agosto de 2016, o Senado Federal cassou o mandato da presidenta.

Este processo de retomada do poder é recheado de propostas neoliberais e libertárias, tais como liberdade absoluta para o mercado 
(ou seja, para o capital), privatização, Estado mínimo e fim de políticas de redistribuição, e nele intervêm várias instituições estrangeiras, empresas norte-americanas e nacionais.

Cumpre registrar, ainda, que, em outubro de 2015, o partido do então vice-presidente da República, que veio assumir o poder após a cassação do mandato da presidente eleita, lançou o programa denominado "uma ponte para o futuro", no qual apresenta várias propostas, que apontam claramente para a proteção do capital, redução das garantias sociais e privatização da disciplina entre capital e trabalho, por meio, principalmente, da adoção da regra da prevalência das convenções coletivas de trabalho sobre a lei, ainda que em prejuízo da condição social dos trabalhadores. ${ }^{1}$

Com esta retomada do poder, ocorreu o que foi registrado, em feliz síntese, por Delfim Netto, para quem "o Brasil deixou o poder econômico controlar a política" e, com isso, "o setor privado anulou a única força que controla o capital, que é o Congresso". ${ }^{2}$ O capital, controlando a política, fez com que fossem editadas normas que asseguram o seu livre desenvolvimento, o que foi, inclusive, publicamente confessado. Neste sentido, em reportagem publicada pelo jornal Folha de São Paulo do dia 24.09.17, foi registrada a fala de representante da Confederação Nacional das Indústrias, no sentido de que tal Confederação apresentou ao presidente em exercício 36 propostas, das quais 29 avançaram, estando entre elas a reforma trabalhista.

O presente artigo pretende contribuir para a definição do significado humano, jurídico, social e político da reforma trabalhista, aqui considerada sob o prisma da Lei n. 13.467/17, bem como apresentar propostas que possam servir de base para a resistência à aludida reforma, sendo nele adotadas três premissas básicas: 1) o lugar que a Constituição da República atribui ao trabalho, aos direitos trabalhistas (direitos inerentes ao trabalho) e ao Direito do Trabalho revela a sua transcendência humana, social e política, que não podem ser negligenciadas no exame de alterações legislativas que os afetam; 2) a Constituição constitui referencial obrigatório na avaliação de toda e qualquer reforma legislativa, não apenas em razão do seu conteúdo, como, também, pelo fato de impor o respeito aos tratados sobre direitos humanos dos quais o Brasil seja signatário, o que exige que toda reforma legislativa seja submetida a controle de constitucionalidade 
e de convencionalidade; 3) direitos fundamentais, humanos e inerentes ao trabalho estão fora da disponibilidade do mercado, como resulta do artigo 60, § 4º, inciso IV, e do artigo 4º , inciso II, da Constituição, valendo chamar a atenção para o fato de que, se comprometer nas relações internacionais com a prevalência dos direitos humanos, é assumir o dever de respeitálos, tutelá-los e realizá-los.

Ademais, proteção da dignidade humana, justiça social, cidadania e democracia não podem ser transformados em moeda de troca no mercado mundial e, com isso, reduzidos à condição de mercadoria.

Releva noticiar, retornando ao vínculo entre poder e Direito, que este não pode ser transformado em simples instrumento de quem detém o poder econômico e político, o que foi desconsiderado pela reforma trabalhista, por meio da qual foram atendidos os anseios dos liberais clássicos: proteção da propriedade (o que se deu, por exemplo, criando dificuldade para o reconhecimento da existência de grupo econômicos - artigo $2^{\circ}$, $\S \S 2^{\circ}$ e $3^{\circ}$, da CLT) e garantia de segurança jurídica (um dos argumentos utilizados para justificar a reforma foi que a atuação dos tribunais trabalhistas, em especial por meio da edição de Súmulas e orientações jurisprudenciais, produzia insegurança jurídica, na medida em que restringia direitos legalmente previstos e criava obrigações que não eram legalmente impostas, o que conduziu ao estabelecimento, pela reforma, do princípio da intervenção mínima na manifestações da autonomia coletiva - art. $8^{\circ}$, $\S \S 2^{\circ}$ e $3^{\circ}$, da CLT $^{3}$ ) e liberdade (entendase, a "liberdade de contratação e mercado", inclusive para desconstruir, por meio da negociação coletiva e até mesmo do contrato individual, normas democraticamente instituídas - prevalência do negociado ou do contrato individual de trabalho sobre a lei - art. 611-A, 620 e 444, parágrafo único, da CLT). ${ }^{4}$

0 presente artigo tem como pressuposto o reconhecimento da necessidade de resistir à reforma trabalhista e pretende lançar luzes sobre aquilo que ela representa, em nome do quê resistir e como resistir.

A tese central defendida no presente artigo é que a reforma trabalhista faz parte de um projeto político neoliberal, cujo objetivo é instituir uma nova ordem social, econômica e política, contrária, inclusive, àquela definida pela Constituição da República, especialmente nos artigos 1ํㅗㅇㅜㅜ 170, 186 
e 193, que impõem a harmonia entre os interesses do trabalho e capital fundada na valorização do trabalho humano, o que explica, inclusive, a afirmação, já noticiada, de que a Constituição de 1988 é, dentre as que já tivemos, "a pior de todas", "pior", certamente, porque contraria os objetivos do projeto político neoliberal.

O presente artigo, no qual é adotada como metodologia a revisão bibliográfica e o método dedutivo, é composto por uma introdução e seis capítulos, aos quais se seguem considerações finais e referências.

A introdução contém a definição do objeto do artigo, as premissas básicas nele adotadas e o seu objetivo. 0 primeiro capítulo visa definir o lugar que a Constituição da República conferiu ao trabalho. 0 segundo capítulo trata do trabalho como direito e do direito ao trabalho com direitos e da relação entre direitos trabalhistas e a realização da justiça social. No terceiro capítulo é examinada a relação entre trabalho, direitos inerentes ao trabalho, cidadania e democracia. 0 quarto capítulo trata do lugar que a Constituição conferiu ao Direito do Trabalho. O quinto capítulo é reservado ao exame da reforma trabalhista enquanto parte de um projeto político neoliberal e dos seus efeitos sociais, econômicos e políticos. No sexto capítulo são apresentadas propostas que possam servir de base para a resistência à aludida reforma.

A reforma trabalhista tem suscitado acalorados debates sobre o seu conteúdo e alcance, fato que confere relevância ao presente artigo, que pretende contribuir para a definição do seu significado e construção de bases para a ela resistir.

\section{O TRABALHO NA CONSTITUIÇÃO DA REPÚBLICA}

Já no seu primeiro artigo, a Constituição faz referência ao trabalho (artigo 1ํㅜㄴ inciso IV), o que indica que ele tem lugar de destaque na ordem social, jurídica, econômica e política.

A Constituição não se limitou a fazer referência ao trabalho, posto que lhe atribuiu, no artigo mencionado, valor social, considerando-o, deste modo, como um ato social e, portanto, de interesse da sociedade. 0 reconhecimento do valor social do trabalho é reiterado em outros 
comandos constitucionais, como, por exemplo, o artigo 170, caput, segundo o qual a ordem econômica é fundada na valorização do trabalho humano, e o artigo 193, que atribui ao primado do trabalho a condição base da ordem social, sendo relevante, ainda, a criação de órgãos jurisdicionais especiais voltados à realização concreta dos direitos inerentes ao trabalho e garantia de efetividade do Direito do Trabalho (artigos 92, inciso II, e 114). Em relação a este último aspecto, é revelador o fato de a reforma trabalhista ter se esmerado na criação de entraves para o acesso dos trabalhadores à justiça, sob o argumento de que havia excessivo e malicioso ajuizamento de demandas perante a Justiça do Trabalho, quando os fatos demonstram que o problema não está no acesso à justiça, mas no excesso de descumprimento da legislação trabalhista. ${ }^{5}$

A Constituição, além de conferir valor social ao trabalho, o fez ao definir os princípios fundamentais da República Federativa do Brasil enquanto Estado Democrático de Direito. Assim, o valor social do trabalho recebeu, da Constituição, o status de princípio fundamental do Estado Democrático de Direito, o que é de suma relevância, na medida em que os princípios têm entre as suas funções a de servirem de parâmetro para a ação e a Constituição também define as ações a serem desenvolvidas pelo Estado, como se vê no seu artigo $3^{\circ}$, que fixa os objetivos fundamentais da República Federativa do Brasil, quais sejam, construir uma sociedade livre, justa e solidária, garantir o desenvolvimento nacional, erradicar a pobreza e a marginalização, reduzir as desigualdades sociais e promover o bem de todos. ${ }^{6}$

Deste modo, o Estado brasileiro tem o dever de perseguir, em todas as suas formas de atuação, a construção de uma sociedade livre, justa, solidária, desenvolvida, com o menor índice possível de pobreza e desigualdades sociais, inclusiva e que promova o bem de todos, adotando como parâmetro, ao fazê-lo, o valor social do trabalho. Trata-se, em suma, do dever de respeitar e fazer respeitar os princípios fundamentais da República e realizar os objetivos eleitos pela Constituição como fundamentais, dever que é reforçado quando a Constituição estabelece que constitui competência da União, dos Estados, do Distrito Federal e dos Municípios, além de zelar pela guarda da Constituição e das instituições democráticas, combater as causas de pobreza e os 
fatores de marginalização, promovendo a integração social dos setores desfavorecidos (artigo 23, incisos I e III).

Assim, o reconhecimento do valor social do trabalho resulta da relevância de suas funções, dentre as quais a função emancipatória (por meio do trabalho e dos direitos a ele inerentes, o trabalhador se torna livre, em menor ou maior medida, da necessidade e, com isto, da submissão à vontade de outrem), função produtiva ou econômica (o trabalho, em especial o realizado no desenvolvimento de atividade econômica, contribui para a criação de riqueza e, com isto, para o desenvolvimento) e função redistributiva (por meio do trabalho e dos direitos que lhe são inerentes, o trabalhador participa, em menor ou maior medida, da distribuição da riqueza gerada pelo trabalho), além do que, segundo a Constituição, ele é uma via de acesso a uma existência conforme à dignidade humana, na medida em que aos direitos inerentes ao trabalho humano foi conferido o status de direitos fundamentais.

\section{TRABALHO COMO DIREITO. DIREITO AO TRABALHO COM DIREITOS, FUNDAMENTAIS, HUMANOS E DE JUSTIÇA SOCIAL}

Por ter o trabalho um valor social, a Constituição o considera um direito fundamental social (artigo 6ํㅜ) e, indo além, assegura o direito ao trabalho com direitos, individuais e coletivos ( $\operatorname{artigos} 7^{\circ}$ a 11). ${ }^{7}$ Mais do que isto, a Constituição reconhece o direito ao trabalho com direitos fundamentais, valendo anotar, no particular, a advertência de Joaquim Herrera Flores, no sentido de que:

A dignidade humana é um fim material. Um objetivo que se concretiza no acesso igualitário e generalizado aos bens que fazem com que a vida seja 'digna' de ser vivida [...]. A dignidade consiste na obtenção de acesso igualitário aos bens tanto materiais como imateriais que se foram conseguindo no constante processo de humanização do ser humano [...]. Viver com dignidade [...] em termos materiais significa gerar processos igualitários de acesso aos bens materiais e imateriais que conformam o valor da 'dignidade humana' (FLORES, 2006, on line). 
Destarte, os direitos fundamentais são inerentes à dignidade humana "no sentido de que sem o seu gozo efetivo não se terá uma vida conforme a dignidade humana, ou seja, os direitos fundamentais são direitos cujo gozo é uma exigência da dignidade humana" (ALMEIDAc; ALMEIDAw, 2017, p. 90).

Ademais, a Constituição dispõe, no artigo 4º , inciso II, que a República Federativa do Brasil rege-se, nas suas relações internacionais, pelo princípio da prevalência dos direitos humanos e, no artigo 5ํㅜ $§ 2^{\circ}$, que os direitos e garantias nela expressos não excluem outros decorrentes dos tratados sobre direitos humanos em que República Federativa do Brasil seja parte. Deste modo, a Constituição reconhece o direito ao trabalho com direitos humanos, lembrando que o gozo dos direitos humanos, dentre os quais os trabalhistas, é também uma exigência da dignidade humana. ${ }^{8}$

Ao reconhecer o direito ao trabalho com direitos fundamentais e humanos, a Constituição estabelece a relação entre trabalho, direitos trabalhistas e dignidade humana, o que indica que, segundo ela, o trabalho com direitos é uma via de acesso à existência conforme a dignidade humana, o que é realçado pelo art. 170, caput, da Constituição, vez que, segundo ele, a ordem econômica é fundada na valorização do trabalho humano e tem por fim assegurar a todos a existência digna.

Abre-se um parêntese para chamar a atenção para o risco da excessiva subjetivação do conceito de dignidade humana, na medida em que, como adverte Béatrice Maurer, "se a dignidade não possui nada de objetivo, a discussão" sobre o seu conceito perde o sentido (MAURER, 2005, p. 62). Atento a esta advertência, no presente artigo tem-se que a pessoa humana possui uma dignidade e que o gozo de direitos fundamentais e humanos constitui uma exigência do respeito a esta dignidade, observando-se que "a dignidade do homem exige que ele respeite não somente a dignidade do outro, mas também a sua, sendo ambas, aliás, inseparáveis" (MAURER, 2005, p. 83).

De outro lado: dos artigos $1^{\circ}$, inciso IV, $3^{\circ}$, inciso I, 4으, inciso II, 5으, $\S 2^{\circ}$, e $6^{\circ}$ a 11 da Constituição é extraído que o trabalho com direitos fundamentais e humanos constitui pressuposto para a construção de uma sociedade justa; no artigo 170, caput, a Constituição dispõe que a ordem econômica, fundada na valorização do trabalho humano, tem 
por fim assegurar a todos uma existência digna, conforme os ditames da justiça social, observando-se que, neste mesmo artigo, a Constituição estabelece que um dos princípios da ordem econômica é a busca do pleno emprego, ou seja, a busca pelo estabelecimento de relações de trabalho à qual correspondem direitos fundamentais e humanos, isto é, trabalho com direitos; a Constituição prevê, no 193, que a ordem social tem base o primado do trabalho e como objetivo a justiça social.

Em suma, direitos inerentes ao trabalho são direitos de justiça social.

\section{TRABALHO. DIREITOS INERENTES AO TRABALHO COMO DIREITOS DE CIDADANIA E DEMOCRACIA}

Os direitos fundamentais que a Constituição assegura aos trabalhadores nos artigos 7ํㅜ a 11 estão incluídos no Capítulo no qual ela trata dos direitos fundamentais sociais (Título II, Capítulo II). Como os direitos sociais são direitos de cidadania, os direitos inerentes ao trabalho são direitos de cidadania. ${ }^{9}$

A relação entre direitos trabalhistas e cidadania é realçada por Boaventura de Souza Santos, para quem

A regulação do tempo de trabalho, das condições de trabalho e do salário, a criação de seguros sociais obrigatórios e de segurança social, o reconhecimento da greve, dos sindicatos e negociação e contratação coletiva são momentos decisivos do longo percurso histórico da socialização da economia. Por ele se foi reconhecendo que a economia capitalista não era apenas constituída por capital, fatores de produção e mercado, mas também por trabalhadores, pessoas e classes com necessidades básicas, interesses próprios e legítimos e, em suma, direitos de cidadania (SANTOS, 2002, p. 12). ${ }^{10}$

É no mesmo sentido a lição de António Cassimiro Ferreira, sendo o trabalho um "ato social" e uma "atividade pública coletiva", o Direito "tem de reconhecer a utilidade geral da atividade do trabalhador, bem como o elo indissolúvel que liga o trabalho à sociedade, enquadrando o trabalho num sistema de direitos e de deveres orientados pelas suas características políticas, sociais, públicas e coletivas onde se escorará a cidadania social" (FERREIRA, 2002, p. 261). Ainda neste mesmo sentido, assinala Robert 
Castel que o pleno exercício da cidadania social pressupõe um mínimo de recursos e de direitos sociais que estão na "base da independência social dos indivíduos” (CASTEL, 2011, p. 107).

Os direitos sociais, dentre eles os trabalhistas, são condição para o exercício de direitos políticos e vice-versa, anotando Zygmunt Bauman, neste sentido, que "se os direitos políticos são necessários para que se estabeleçam os direitos sociais, estes são necessários para que os direitos políticos se tornem 'reais' e se mantenham em operação. Os dois tipos de direitos precisam um do outro para sobreviver; sua sobrevivência só pode ser uma realidade conjunta" (BAUMAN, 2013, p. 22).

Assim, além de assegurar o acesso a direitos sociais, devem ser estabelecidos procedimentos e instrumentos que permitam a participação concreta dos indivíduos na tomada de decisões coletivas, ou seja, a cidadania social deve ser complementada pela cidadania política. Com efeito, cidadania significa participação não apenas na distribuição de riqueza por meio de direitos, como também na tomada de decisões coletivas, ou seja, cidadão é aquele que participa da tomada de decisões coletivas, isto é, do poder político.

Deve ser rechaçada, no entanto, a concepção minimalista da cidadania, que a reduz à possibilidade de participação na eleição dos governantes de determinado país, em especial quando conduz à uma concepção minimalista da democracia, reduzindo-a ao espaço meramente eleitoral (à democracia em sentido procedimental - democracia é uma forma de governo na qual o poder de decisão pertence ao povo e exercido de acordo com regras por ele próprio definidas - deve-se somar em sentido substancial - poder exercido em favor do povo, ou seja, do bem comum).

A cidadania ativa constitui uma condição de possibilidade da democracia, na medida em que não existe democracia na ausência de cidadania ativa.

Ademais, os direitos inerentes ao trabalho, sendo direitos de cidadania, são, também, direitos de democracia, lembrando, inclusive, que "a ideia de democracia não pode ficar separada da ideia de direitos" (TOURAINE, 1996, p. 38), o que significa que reconhecer o direito ao trabalho com direitos é também uma exigência da democracia. ${ }^{11}$ 
Neste compasso, inclusive, os direitos inerentes ao trabalho são verdadeiros poderes, vez que, por meios deles, os trabalhadores adquirem condições materiais (direitos que asseguram a liberdade e a igualdade) e jurídicas (direitos traduzidos por instrumentos de ação coletiva: sindicatos, negociação coletiva e greve) necessárias para a participação da tomada de decisões coletivas, assinalando Gerardo Pisarello a propósito que direitos são

[...] instrumentos dirigidos a proteger determinados interesses radicais das pessoas frente aos abusos e à arbitrariedade do poder. Do poder estatal, mas também do poder do mercado. Esgrimir um direito pressupõe reivindicar um interesse ou uma necessidade não suscetível de converter-se em uma mercadoria ou em simples elemento de regateio entre partidos. Neste sentido, a própria história dos tempos modernos tem sido, em certo modo, a história de uma série de lutas, árduas e díspares, pela conquista de direitos, de contrapoderes capazes de conter, em âmbitos diferentes, os efeitos opressivos de micro e macro poderes que, desprovidos de limites e controles, representam uma ameaça para a autonomia individual e coletiva das pessoas, sobretudo dos membros mais débeis e vulneráveis (PISARELLO, 2001-2002, p. 91).

De outro lado, enquanto limites aos poderes do capital, os direitos inerentes ao trabalho atuam como verdadeiros contrapoderes, sendo relevante, também neste sentido, a lição de Gerardo Pisarello, para quem os direitos constitucionais, dentre os quais os sociais, podem ser representados como "verdadeiros contrapoderes dirigidos a contrastar os poderes arbitrários capazes de influenciar de maneira unilateral na esfera de atuação das pessoas" (PISARELLO, 2001-2002, p. 100), o que é também sustentado por Luigi Ferrajoli (FERRAJOLI, 2014, p. 25).

Em suma, os direitos inerentes ao trabalho constituem direitos/ poderes/contrapoderes emancipatórios, no sentido de "elementos igualitários e de autonomia, orientados a ampliar o autogoverno das pessoas e a liberdade do medo e da necessidade" (PISARELLO, 20012002, p. 92), direitos/poderes/contrapoderes políticos, na medida em que criam as condições necessárias para o exercício da cidadania ativa e realização da democracia, e direitos/poderes/contrapoderes econômicos, enquanto limites impostos aos poderes públicos e privados. 
Note-se que, como riqueza é poder e a justiça social exige a distribuição de riquezas da forma mais equânime possível, a Constituição, inclui entre os objetivos da República a construção de uma sociedade livre, justa e solidária, a busca pelo desenvolvimento econômico, social, cultural e político, a redução das desigualdades sociais e a busca do bem comum (artigo $3^{\circ}$, incisos II, III e IV) e dispõe que a propriedade cumpre a sua função social quando realiza o bem-estar de proprietários e trabalhadores (artigo 186, inciso IV), sendo relevante acrescentar, ainda, que a democracia "está nua em sua relação com o poder da riqueza" (RANCIÈRE, 2014, p. 122). Isto significa que a Constituição reconhece que a democracia exige distribuição o mais equânime possível da riqueza. Tal fato conduz à afirmação de que direitos inerentes ao trabalho humano são, também, instrumentos de justiça social e, portanto, de democracia.

Ademais, concentração de riqueza significa concentração de poder e anulação do pluralismo exigido pela democracia. ${ }^{12}$ Não é por outra razão que a Constituição reconhece o direito à igualdade (artigo 5으, caput) e inclui entre os objetivos fundamentais da República a redução das desigualdades sociais (artigo 3o, inciso III), o que implica reconhecer que a igualdade é também uma condição de possibilidade da democracia.

Portanto, direitos inerentes ao trabalho são direitos justiça social, igualdade e democracia. ${ }^{13}$

\section{DIREITO DO TRABALHO E CONSTITUIÇÃO DA REPÚBLICA}

A Constituição reconhece a existência do Direito do Trabalho como ramo autônomo do Direito, o que faz quando atribui à União a competência privativa para sobre ele legislar (artigo 22, inciso I).

O lugar que a Constituição atribui ao trabalho e aos direitos a ele inerentes se comunica às normas que o disciplinam, ou seja, ao Direito do Trabalho. Deste modo, chega-se à conclusão de que o Direito do Trabalho, por força constitucional, possui valor social e constitui meio para a realização dos objetivos fundamentais da República Federativa 
do Brasil e instrumento de concretização da dignidade humana, cidadania e democracia.

Não fosse isto, a Constituição atribui significado especial ao Direito do Trabalho de forma expressa. É que, ao definir, no artigo 186, as condições em que a propriedade cumprirá a sua função social, a Constituição inclui entre elas o respeito ao Direito do Trabalho (inciso III), valendo anotar que este dispositivo constitucional não faz alusão a qualquer outro ramo do Direito, em uma clara demonstração de que atribui ao Direito do Trabalho um lugar estratégico na conformação da ordem social e econômica. 0 Direito do Trabalho é estratégico porque, como foi demonstrado, constitui um Direito de dignidade humana, justiça social, cidadania e democracia. Com isto, inclusive, os ataques ao Direito do Trabalho são, na essência, ataques à dignidade humana, justiça social, cidadania e democracia.

Norberto Bobbio assinala, a propósito do ataque à democracia, que

[...] A ofensiva dos liberais voltou-se historicamente contra o socialismo, seu natural adversário na versão coletivista [...]; nestes últimos anos, voltou-se contra o estado do bem-estar, isto é, contra a versão atenuada (segunda uma parte da esquerda, também falsificada) do socialismo; agora é atacada a democracia, pura e simplesmente [...]. Não está em jogo apenas o estado do bem-estar, quer dizer, o grande compromisso histórico entre o movimento operário e o capitalismo maduro, mas a própria democracia, quer dizer, o outro grande compromisso histórico precedente entre o tradicional privilégio da propriedade e o mundo do trabalho organizado, do qual nasce direta ou indiretamente a democracia moderna (através do sufrágio universal, da formação de partidos de massa, etc.) (BOBBIO, 1986, p. 126).

Como a democracia é fragilizada por meio da fragilização das suas condições de possibilidades, entre as quais a garantia de acesso a direitos de dignidade humana, justiça social e cidadania, o neoliberalismo se volta contra a democracia quando dificulta a satisfação destes direitos e/ou os nega aos trabalhadores.

É relevante anotar que a reforma trabalhista reduz, de forma marcante, o papel dos sindicatos, permitindo a instituição de banco de horas por meio de acordo individual, autorizando a adoção do regime 12x36 horas por acordo individual, com possibilidade, inclusive, do estabelecimento 
do trabalho por 12 horas seguidas, sem gozo do intervalo para descanso e refeição e homologação sindical das rescisões contratuais, por exemplo, e, ao mesmo tempo, reforça os poderes do capital, o que realiza, por exemplo, quando institui a modalidade de acordo tácito de prorrogação da jornada de trabalho, permite prorrogação da jornada no caso de força maior ou para atender à realização ou conclusão de serviços inadiáveis cuja execução possa acarretar prejuízo manifesto, sem necessidade de comunicação à autoridade competente em matéria trabalhista, ${ }^{14}$ possibilita ao empregador, por ato unilateral, alterar o regime de teletrabalho para regime presencial, aumenta a liberdade para a diferenciação salarial e estabelece que a dispensa coletiva independe de prévia autorização sindical ou da celebração de acordo ou convenção coletiva. ${ }^{15}$

Tudo isto resulta em prejuízo da democracia, na medida em que não há democracia "sem autonomia de formações sociais e o que elas significam enquanto ação de representação e tutela dos interesses dos trabalhadores em seu conjunto, enquanto membros de um grupo social determinado" e "sem que nela se instalem os sindicatos como agregações de interesses juridicamente prementes e politicamente relevantes que se configuram como instâncias de emancipação social" (BAYLOS, 2002).

A reforma trabalhista impõe a prevalência do negociado sobre o legislado e, em algumas situações, do contrato individual de trabalho sobre o legislado, o que implica distanciamento do Estado da disciplina da relação entre capital e trabalho, ou seja, o estabelecimento do Estado mínimo, em favor de leis supostamente invisíveis do mercado, valendo anotar que a prevalência do negociado sobre o legislado se dá em contexto de flagrante enfraquecimento dos sindicatos e reforço dos poderes do capital, o que implica dizer que o que prevalecerá, sob o manto do exercício da autonomia coletiva, será a edição de normas ditadas pelos interesses do capital, conforme as leis supostamente "invisíveis do mercado".

Neste particular, como adverte Norberto Bobbio, "a presença de um poder invisível corrompe a democracia”, na medida em que a democracia possui entre as suas características a "visibilidade ou a transparência do poder" (BOBBIO, 1986, p. 10-11).

Anote-se que a ação coletiva, por meio dos sindicatos, é um contrapoder em face do absolutismo do Estado e capital. Neste sentido, 
Gregorio Peces-Barba afirma que as associações limitam e impedem as tentações totalitárias do poder político, na medida em que atuam como fator de equilíbrio e contrapeso (MARTÍNEZ,1995, p. 46-48), ao passo que, consoante Norberto Bobbio, "os grupos e não os indivíduos são os protagonistas da vida política numa sociedade democrática” (BOBBIO, 1986, p. 2). Enfraquecer a ação coletiva e o seu principal instrumento (sindicatos) e, nesta ordem de ideias, precarizar a democracia.

É de se ter presente, no exame da relação entre reforma trabalhista e democracia, que, com a submissão do Estado ao mercado internacional, as decisões de política social e econômica são subtraídas do controle popular e político, em inegável prejuízo à cidadania e democracia.

Acrescente-se que a verdadeira democracia é aquela em que os direitos são reconhecidos e feitos valer concretamente quando desrespeitados, o que justifica, inclusive, o fato de ser o direito de ação ser considerado um direito humano por várias normas que compõem o Direito Internacional dos Direitos Humanos, entre elas a Declaração Universal dos Direitos Humanos. ${ }^{16}$

\section{SOCIEDADE, HOMEM E ESTADO NEOLIBERAIS. A ERA DO PÓS-DIGNIDADE HUMANA, PÓS-JUSTIÇA SOCIAL, PÓS- CIDADANIA E PÓS-DEMOCRACIA}

A reforma trabalhista foi realizada em contexto de tomada de poder pelo capital, constituindo, portanto, parte do processo de adaptação da ordem social, jurídica econômica e política aos seus interesses, mas é, antes de tudo, parte de um projeto político globalizando, que reduz a sociedade a uma empresa constituída por empresas, em concorrência permanente.

Com a implantação deste projeto, o trabalhador é levado a agir como "empresa de si mesmo", não se enxergando mais como um trabalhador, "mas como uma empresa que vende um serviço em um mercado", "como entidade em competição e, que, por isso, deve maximizar seus resultados, expondo-se a riscos e assumindo inteira responsabilidade por eventuais fracassos. 'Empresa' é também o nome que se deve dar ao governo de si na era neoliberal" (DARDOT; LAVAL, 2016, p. 328 e 334), o que conduz 
a um verdadeiro "culto à empresa e ao empreendedor" (DARDOT; LAVAL, 2016, p. 289). ${ }^{17}$

Este fenômeno é também assinalado por Ulrich Beck, para que, de acordo com o projeto político neoliberal, "a vida própria é projetada como uma empresa, e, diante dela, é preciso se comportar como capitalista" (BECK, 2003, p. 72).

Ressalte-se que o projeto em destaque vem sendo implementado há vários anos, observando-se, neste sentido, que Margaret Thatcher afirmou em 1981, que "a economia é o método. 0 objetivo é mudar o coração e a alma" (Sunday Times, 03.05.81, on line), ou seja, mais do que impor as leis do mercado, o que se pretendia e vem sendo realizado é a mudança do "coração" e da "alma" dos trabalhadores, que são levados a pensar e agir como empresas. ${ }^{18} 0$ trabalhador, agindo como empresa, coloca no mercado a sua mercadoria, qual seja, o seu trabalho, operando-se a "'cumplicidade estrutural' que une ao capital, na medida em que 'ganhar dinheiro', cada vez mais dinheiro, é o objetivo determinante de ambos" (DARDOT; LAVAL, 2016, p. 401), observando-se que, neste contexto, ganha força tese do libertarismo segundo a qual "a liberdade é justificada pela propriedade de si mesmo" (FERREIRA, 2014, p. 86), o que pode conduzir, por exemplo, a possibilidade de a pessoa "colocar o seu corpo no mercado e vender-se como escravo" (FERREIRA, 2014, p. 87).

Transformado em mercadoria, o trabalho se desvincula da dignidade humana, justiça social, cidadania e democracia, passando a ser valorizado na perspectiva de sua participação em um processo de troca de valores econômicos, no qual predominam interesses individuais e o princípio da solidariedade é substituído pelo da concorrência.

Por sua vez, o Estado abandona o seu papel de promotor do desenvolvimento econômico, social e político, tornando-se um agente do mercado, que adota uma "Nova política 'social', que visa maximizar a utilidade da população, aumentando a sua 'empregabilidade' e produtividade e diminuir seus custos, com um novo gênero de política 'social' que consiste em enfraquecer o poder de negociação dos sindicatos, degradar o direito trabalhista, baixar o custo do trabalho, diminuir o valor das aposentadorias e a qualidade da proteção social em nome da 'adequação à globalização' (DARDOT; LAVAL, 2016, p. 285), ao que deve ser 
acrescentado o fortalecimento da intervenção do Estado na área econômica para a “'proteção' e viabilização das empresas", estabelecendo-se uma espécie de "'Estado Providência das empresas"” (SANTOS, 1991, p. 160) ou "Estado máximo na promoção do mercado" (FERREIRA, 2014, p. 63).

Pierre Dardot e Christian Laval afirmam que o neoliberalismo é antidemocrático e conduz à era do pós-democracia, sustentando, neste sentido, que, para eles

[...] 0 direito privado deveria ser isentado de qualquer deliberação e qualquer controle, mesmo sob a forma de sufrágio universal (...). Esse sistema fechado impede qualquer autocorreção de trajetória, em particular em razão da desativação do jogo democrático e até mesmo, sob certos aspectos, da política como atividade. 0 sistema neoliberal está nos fazendo entrar na era pós-democrática [...]. A democracia repousa sobre a soberania de um povo [...]. Enquanto doutrina, o neoliberalismo é, não acidentalmente, mas essencialmente, antidemocrático (DARDOT; LAVAL, 2016, p. 8 e 384).

Acrescente-se que "o neoliberalismo não é apenas uma ideologia, um tipo de política econômica. É um sistema normativo que ampliou sua influência ao mundo inteiro, estendendo a lógica do capital a todas as relações sociais e a todas as esferas da vida" (DARDOT; LAVAL, 2016, p. 7). Portanto, o neoliberalismo impõe regras e princípios, de forma que é estabelecida "uma forma norma e crescentemente abstrata de dominação, que sujeita as pessoas a imperativos e coerções estruturais impessoais que não podem ser adequadamente compreendidas em termos de dominação concreta (por exemplo, dominação pessoal ou de grupo)" (POSTONE, 2014, p. 18).

Tudo que o foi exposto permite afirmar que a reforma trabalhista é parte de um projeto político mais amplo. Neste sentido, vale anotar que Boaventura de Sousa Santos dá notícia de reportagem publicada no The Wall Street Journal em abril de 2018, após a condenação do ex-presidente Lula em segunda instância, que demonstra bem a quem beneficiou a construção da "ponte para o futuro". Segundo esta reportagem, "o mercado delirou" com a condenação, principalmente porque ela aumentava a possibilidade de Lula não ser candidato nas próximas eleições presidenciais, além do que, “a decisão é boa para o Brasil: ela dá sinal de que o Judiciário está a 
ficar mais independente, e o estado de direito está a atingir maturidade. Trata-se de um desenvolvimento para a economia bem maior que qualquer descoberta de petróleo ou fenomenal cultura de soja" (SANTOS, 2018, p. 18-19). Portanto, o mercado interferiu na queda da presidenta e "delirou" com a possibilidade da não participação de Lula nas próximas eleições presidenciais.

Assim, conjugados todos os efeitos da política neoliberal, na qual se insere a reforma trabalhista, é lícito afirmar que ela conduz à era: a) pósdignidade humana: o trabalhador não possui um valor em si mesmo, mas um preço, fixado segundo as leis do mercado; b) pós-justiça social: políticas de distribuição de rendas e de poder são substituídas pelo incentivo à luta pelo sucesso individual, realizada, inclusive, por pessoas que se sentem e agem como empresas, e de transferência de renda da classe trabalhadora para o capital e a consequente concentração de poder nas mãos de seus detentores; c) pós-cidadania: os trabalhadores não participarão da tomada de decisões coletivas voltadas ao bem-comum, mas estarão submetidos às "leis invisíveis e naturais do mercado"; d) pós-democrática: as decisões fundamentais são impostas ao Estado e à sociedade pelo mercado global, com o consequente aniquilamento ou enfraquecimento da classe trabalhadora enquanto agente político, para o qual contribui, ainda, a "difusão social da produção", que é, antes de mais nada, "a fragmentação geográfica e social do processo de trabalho" (SANTOS, 1991, p. 155) e, portanto, da classe trabalhadora.

Já foi afirmado que o princípio basilar do Direito do Trabalho, que é o da proteção do trabalho, deve ser abandonado, como exigência da competitividade e da economia, que "preconizam o triunfo do mercado e impõem a flexibilização das condições de trabalho como condição de redução de custos da empresa" (ROMITA, 1997, p. 24). No entanto, é preciso ter presente que dignidade humana, justiça social, cidadania e democracia não podem ser subordinadas a interesses meramente econômicos. A economia serve ao homem e não o contrário.

Ressalte-se, em relação ao ataque à cidadania e à democracia, que no Congresso do Agronegócio já referido foi dito que cabe à elite dirigir os destinos do país, o que afronta a Constituição, que adota como princípio fundamental da República o pluralismo político (art. 1ํ, V) e, como forma 
de governo, a democracia (art. 1ำ, caput), indicando que os destinos do país devem ser democraticamente definidos e não submetidos aos interesses de uma classe social.

\section{A RESISTÊNCIA À REFORMA TRABALHISTA E AO QUE ELA REPRESENTA}

Para "evitar uma nova era de barbárie", é indispensável "alimentar um espírito de resistência [...] no terreno do trabalho teórico (que nos ajuda a compreender a realidade para melhor intervir sobre ela) e no terreno da luta ideológica (que nos ajuda a desmascarar a ideologia dominante e a combater os interesses estabelecidos e as ideias feitas), porque a luta ideológica é, hoje mais que nunca, um campo decisivo na luta política e na luta social", visando à construção de um "projeto político alternativo" (NUNES, 2013, p. 374), que se assente no valor social do trabalho, dos direitos inerentes ao trabalho humano e do Direito do Trabalho como vias de acesso à existência conforme a dignidade humana, justiça social, cidadania e democracia.

Em resposta à reforma trabalhista é necessário e urgente: 1) respeitar e fazer respeitar a força normativa da Constituição da República e dos tratados internacionais sobre direitos humanos; 2) respeitar, tutelar e realizar os direitos fundamentais, direitos humanos e os direitos de dignidade humana, justiça social, cidadania e democracia, entre eles os que são inerentes ao trabalho humano, não se olvidando, ainda, da indispensável facilitação do acesso à justiça, como instrumento de acesso àqueles direitos; 3 ) compreender que a defesa do trabalho, dos direitos trabalhistas e do Direito do Trabalho não pode se limitar ao campo econômico, na medida em que eles possuem transcendência econômica, mas também e principalmente, transcendência humana, social e política, assim como, que, se os efeitos dos ataques à dignidade humana, justiça social, cidadania, democracia e ao Direito do Trabalho são sentidos em cada Estado, a sua proteção há de ser local e global, vez que decisões de política econômica e social são hoje tomadas por empresas multinacionais, com predomínio das financeiras, que contam com os Estados nacionais 
como instrumento para reduzir custos da mão-de-obra, socializar custos e combater qualquer tentativa de resistência.

A política neoliberal insiste na análise apenas econômica do Direito do Trabalho

[...] as críticas econômicas ao direito do trabalho têm constituído uma narrativa relevante, essencialmente anti-trabalhador e anti-sindical, e esta narrativa tem influenciado eficazmente muitos legisladores e políticas públicas, por meio da busca de flexibilidade trabalhista e desregulações. Isto é o que Schwab denomina 'a invasão econômica do direito do trabalho' (GAMONAL, 2017, p. 7).

A estas críticas têm que se opor a afirmação da transcendência humana, social e política do trabalho, dos direitos trabalhistas e do Direito do Trabalho, devendo este ser invadido, não pelos princípios econômicos, mas por anseio de dignidade humana, justiça social, cidadania e democracia, lembrando que, como afirmam Hans-Peter Martin e Harald Schumann, "quanto mais a desigualdade material ameaçar a coesão das sociedades, tanto mais importante é que os próprios cidadãos defendam os direitos democráticos básicos e fortaleçam a solidariedade social" (MARTIN; SCHUMANN, 1998, p. 330-331).

Em suma, é necessário e urgente opor à reforma trabalhista uma postura de dupla recusa "a recusa de se conduzir em relação a si mesmo como uma empresa e de se conduzir em relação aos outros de acordo com a norma da concorrência" (DARDOT; LAVAL, 2016, p. 400), mas, principalmente, uma postura ativa, de luta pela recuperação da dimensão humana das relações sociais e pela reconstrução dos caminhos que levam à justiça social, cidadania e democracia.

Lembre-se que "o direito ao fim confere direito aos meios necessários para aquele fim" e que é "vão alguém ter direito ao fim se for negado o direito aos meios que sejam necessários" (HOBBES, 1992, p. 35-36). Portanto, dignidade humana, justiça social, cidadania e democracia serão vazios de sentido sem acesso real aos direitos voltados à sua realização concreta. 


\section{CONSIDERAÇõES FINAIS}

O presente artigo versa sobre o significado humano, social e político da reforma trabalhista, aqui considerada na perspectiva da Lei n. 13.467/17.

No seu desenvolvimento, chegou-se à conclusão de que o lugar que a Constituição da República atribuiu ao trabalho, aos direitos trabalhistas e ao Direito do Trabalho impede que se adote, em relação às alterações legislativas que os afetam, uma visão reducionista, com a limitação dos seus efeitos a uma questão de mais ou menos direitos de feição econômica, e que o trabalho, os direitos trabalhistas e o Direito do Trabalho são vias de acesso à dignidade humana, justiça social, cidadania e democracia, o que implica que a reforma trabalhista possui consequências humanas, sociais e, políticas.

Também foi constatado que a reforma trabalhista faz parte de um projeto político neoliberal, cujo objetivo é instituir uma nova ordem jurídica, social, econômica e política, contrária, àquela definida pela Constituição da República, especialmente nos artigos 1ํㅜ 3ํㅜ, 170, 186 e 193, que impõem a harmonia entre os interesses do trabalho e capital, fundada na valorização do trabalho humano.

Com efeito, a reforma trabalhista: criando barreiras para o acesso dos trabalhadores à justiça e ao reconhecimento e satisfação de seus direitos pela via judicial, cria barreira para o acesso, o reconhecimento e a satisfação de direitos de dignidade humana, justiça social, cidadania e democracia; enfraquecendo a ação coletiva dos trabalhadores, impede ou prejudica a sua participação na tomada de decisões coletivas, e, com isto, a sua atuação como cidadãos, em prejuízo da democracia; retirando direitos dos trabalhadores, a eles nega poderes/contrapoderes que impedem a sua submissão social, econômica e política ao capital.

Como foi demonstrado, a reforma trabalhista, contrariando a Constituição da República e Tratados sobre Direitos Humanos, esvazia o valor social do trabalho, dos direitos inerentes ao trabalho e do Direito do Trabalho, o que a torna uma reforma social, econômica e política, vez que conduz, não acidental, mas deliberadamente, à precarização da condição humana dos trabalhadores, justiça social, cidadania e democracia, colocando a todos, não no rumo da modernidade 
e liberdade, mas no da era pós-dignidade humana, pós-justiça social, pós-cidadania e pós-democracia.

Ao final, foi realçado que, em resposta à reforma trabalhista, é necessário e urgente: respeitar e fazer respeitar a força normativa da Constituição da República, os direitos fundamentais e humanos, em especial do direito de acesso à justiça; reconhecer a transcendência humana, social e política do trabalho, dos direitos trabalhistas e do Direito do Trabalho; não agir em relação a si como se fosse uma empresa e, aos outros, de acordo com norma da concorrência; adotar uma postura ativa, de luta pela recuperação da dimensão humana das relações sociais e reconstrução dos caminhos que levam à justiça social, cidadania e democracia;

No entanto, é necessário ter presente que, além do direito de viver de forma digna, atuar como cidadão e participar de uma sociedade justa e democrática, cada pessoa tem o dever de lutar para que todos gozem deste mesmo direito.

\section{NOTAS}

1 Disponível em: https://www.fundacaoulysses.org.br/wp-content/uploads/2016/11/UMA-PONTE-PARA-O-FUTURO.pdf).

2 Trata-se artigo publicado no Jornal Folha de São Paulo, Mercado, A16, 03.07.17.

3 A segurança perseguida, é bom que se diga, não se destina a todos. A reforma trabalhista, neste aspecto, é reveladora de suas reais intenções: foi estabelecida a possibilidade da celebração do contrato de trabalho intermitente, em moldes que submetem o trabalhador à vontade unilateral do empregador, instalando-se, para ele, a ausência de um mínimo de segurança econômica (artigos 443, § 3o, e 452-A); mesmo após exercer mais de dez anos função de confiança, o trabalhador pode ser revertido ao cargo efetivo, sem possibilidade de incorporação da gratificação correspondente ao cargo de confiança, estabelecendo-se, ainda por esta medida, a insegurança econômica (artigo 468, §§ $1^{\circ}$ e 2oㅡ, da CLT); até mesmo a segurança em relação à satisfação dos créditos reconhecidos em juízo foi afetada, por meio do estabelecimento de verdadeira moratória em favor dos empregadores, que, apesar de condenados em decisão transitada em julgado, somente poderão ser protestados, ter o nome inscrito em órgãos de proteção ao crédito ou no Banco Nacional de Devedores - artigo 883-A da CLT); até mesmo a segurança gerada pela obrigação de respeito à Constituição e aos Tratados sobre Direitos Humanos foi atacada, na medida em que, por exemplo, foi estabelecido que, ao julgar pedido de reparação de danos extrapatrimoniais, o juiz deve se ater ao que a respeito dispõe apenas a CLT (art. 223-A).

4 Por meio da prevalência do negociado ou contratado sobre a lei, os trabalhadores são compelidos a uma postura defensiva - defender o mínimo assegurado por lei - como até mesma a uma postura destrutiva - desconstrução negociada das condições de trabalho asseguradas pela lei, para a manutenção de empregos, ainda que precários.

5 Dados do CNJ, relativos ao ano de 2016, demonstram que apenas 7,7\% das demandas trabalhistas foram julgadas totalmente improcedentes naquele ano, ou seja, que $\mathbf{9 2 , 3 \%}$ das demandas submetidas à Justiça do Trabalho foram julgadas total ou parcialmente procedentes, $o$ que deixa clara a falta de efetividade das normas que compõem o Direito do Trabalho, assim 
como que restringir o acesso à justiça é, em 92,3\% dos casos, restringir o acesso aos direitos inerentes ao trabalho, não podendo ser olvidado que, quanto menor a efetividade do Direito do Trabalho, "mais fraca será a condição cidadã do trabalhador" (FERREIRA, 2002, p. 272) e, com isto, a democracia.

6 A Constituição coloca lado a lado o valor social do trabalho e o valor social da livre iniciativa (artigo 1ํㅡㄹ no inciso IV), inclui entre os objetivos fundamentais da República objetivos sociais construção de uma sociedade livre, justa, erradicação da pobreza e marginalização e redução das desigualdades sociais -, e econômicos - desenvolvimento nacional, o que abarca o desenvolvimento econômico, embora a ela não se resuma (artigo $3^{\circ}$ ) e atribui função social à propriedade (artigos $5^{\circ}$, inciso XXIII, e 186) e à atividade econômica (artigo 170, caput), prestigiando-se, assim, duas das dimensões do desenvolvimento sustentável, quais sejam, a social e a econômica.

7 Anote-se que a Constituição se refere ao gênero trabalho (art. 1ํ, inciso IV), mas assegura direitos que pressupõem o trabalho subordinado, ou seja, àquele que é prestado no contexto de uma relação de emprego (artigos 7으 a 11), o que a leva, inclusive, a estabelecer como princípio da ordem econômica a busca do pleno emprego (art. 170, inciso VIII).

8 Neste sentido, a Declaração Universal dos Direitos Humanos e o Protocolo Adicional à Convenção Americana sobre Direitos Humanos em Matéria de Direitos Econômicos Sociais e Culturais reconhecem o direito ao trabalho digno, que é garantido pelo acesso aos vários direitos a que fazem referência, dentre eles condições justas de trabalho, remuneração justa e satisfatória e organização de sindicatos.

9 É adotada, para os fins do presente artigo, a teoria segundo a qual a cidadania indica o conjunto dos direitos civis, políticos e sociais, isto sem abdicar da consciência de que ela constitui status concedido por determinada comunidade política (cidadão é aquele que participa do poder político, por ser membro da comunidade política na qual aquele poder é exercido; a cidadania, deste modo, está territorialmente fundada, o que implica, inclusive, que ela pode servir de fundamento para negar direitos àqueles que não sejam membros de determinada comunidade), e, ainda, a perspectiva segundo a qual trabalhador possui direitos que lhe cabem em razão da sua condição de pessoa e não decorrem do pertencimento a uma comunidade política (deste modo, apresenta-se um contraponto à ideia de que acesso aos direitos humanos e fundamentais tem como condição o pertencimento a determinada comunidade política). A condição de cidadão do trabalhador não excluiu a de pessoa e, com isto, a titularidade de direitos fundamentais e humanos reconhecidos às pessoas (direitos fundamentais e humanos trabalhistas inespecíficos). 0 reconhecimento de que o trabalhador é, a um só tempo, pessoa e cidadão, faz com que os seus direitos não sejam apenas aqueles reconhecidos por determinada comunidade política. Esta é, inclusive, a ideia que anima o estabelecimento de direitos humanos trabalhistas, enquanto direitos de que o trabalhador é titular na condição de pessoa e cujo respeito e realização constitui obrigação constitui dever da comunidade política a que pertence. Fala-se, a propósito, em cidadania trabalhista, como cidadania de âmbito universal relacionada ao mundo do trabalho. Esta solução, embora resulte no alargamento dos direitos que devem ser reconhecidos ao trabalhador, ainda está presa à ideia de cidadania e, com isto, à de pertencimento a determinada comunidade política. Daí, inclusive, a ideia de cidadania universal como forma de fugir da limitação imposta pela concepção de cidadania como pertencimento. Para vencer esta limitação, basta reconhecer no trabalhador a condição de pessoa e, com isto, de titular de direitos da pessoa. Este debate, no entanto, foge ao objeto do presente artigo. Seja como for, a cidadania pressupõe o gozo efetivo de determinados direitos, dentre eles os sociais e políticos, como direitos complementares e interdependentes.

10 Boaventura de Sousa Santos aduz que "o grau zero da legitimidade do Estado moderno é o fascismo, a rendição total da democracia perante as necessidades de acumulação do capitalismo" (SANTOS, 2002, p. 13). Esse doutrinador adverte, inclusive, para a erupção do que denomina fascismo social, que se manifesta de várias formas, dentre as quais o facismo-para-estatal, caracterizado pela "usurpação de prerrogativas estatais (de coerção e de regulação social) por parte de atores sociais muito poderosos, muitas vezes com a conivência do Estado, que ora neutralizam, ou suplantam o controle social produzido pelo Estado. 0 fascismo para-estatal tem duas vertentes: o fascismo contratual e o fascismo territorial. o fascismo contratual é o que ocorre nas situações [...] em que a diferença de poder entre as partes no contrato de direito civil é de 
tal ordem que a parte mais fraca, vulnerabilizada por não ter alternativa ao contrato, aceita as condições que lhe são impostas pela parte mais poderosa, por mais onerosas e despóticas que sejam. 0 projeto neoliberal de transformar o contrato de trabalho num contrato de direito civil como qualquer outro configura uma situação de fascismo contratual" (SANTOS, 2002, p. 34-35). Aliás, em um Congresso do Agronegócio, um ex-ministro do Trabalho e do Tribunal Superior do Trabalho advogou a tese de que o contrato de trabalho deve ser remetido para o Código Civil e, mais do que isto, considerou a Constituição de 1988 como a pior de todas, ao que parece pelo fato de reconhecer direitos trabalhistas que deveriam ser extirpados da nossa legislação (http:// justificando.cartacapital.com.br/2017/08/08/no-congresso-do-agronegócio-ataques-justiça-do-trabalho-e-constituição).

11 A dignidade humana, a cidadania e a democracia são complementares e interdependentes, observando-se que "numa sociedade dos cidadãos, estes têm direito, e o primeiro dentre eles, é o da dignidade ser reconhecida" (SCHNAPPER, 1998, p. 96).

12 Daí os chefes de Estado presentes na assembleia da ONU na qual foi adotada a Agenda 2030, entre eles o do Brasil, terem reconhecido: a necessidade de construir uma sociedade justa e inclusiva, proteger os direitos humanos, promover a "prosperidade compartilhada e trabalho decente para todos" e respeitar o direito internacional; o direito de todos ao acesso à proteção social e ao bem-estar físico, mental e social; o dever de os Estados respeitarem, protegerem e promoverem os direitos humanos (ns. 7, 11 e 19) e de adotarem políticas que promovam o compartilhamento da riqueza e de combate às desigualdades de renda e de adotarem políticas econômicas centradas nas pessoas (n. 27). Na oportunidade, foram adotadas como metas, a serem atingidas até 2030, "alcançar o emprego pleno e produtivo e trabalho decente para todas mulheres e homens" (Objetivo 8.5), "proteger os direitos trabalhistas" (Objetivo 8.8) e "proporcionar acesso à justiça para todos" (Objetivo 16). Não obstante tudo isso, a reforma trabalhista dificulta o acesso dos trabalhadores à justiça e à satisfação de direitos trabalhistas, não respeita, protege ou promove direitos humanos e nega direitos assegurados pela ordem jurídica, o que implica flagrante desrespeito ao que foi estabelecido pela $\mathrm{ONU}$, com a participação do Brasil, como já foi registrado. (ONU, 2016, on line).

13 Os direitos inerentes ao trabalho constituem técnica destinada ao combate às desigualdades, lembrando, neste sentido, que o objetivo dos direitos sociais, é "a igualdade por meio da satisfação de necessidades básicas, sem a qual muitas pessoas não poderiam alcançar níveis de humanidade necessários para desfrutar de direitos individuais civis e políticos, para participar em plenitude da vida política e para desfrutar seus benefícios (MARTíNEZ, 1998, p. 25).

14 A reforma trabalhista chegou ao ponto de estabelecer que as "regras sobre duração do trabalho e intervalos não são consideradas como normas de saúde, higiene e segurança do trabalho" para efeito de verificação da legalidade de normas constantes de instrumentos coletivos (artigo 611-B, parágrafo único, da CLT), o que, não fosse o fato de não corresponder à realidade, é desmentido pela própria CLT, que trata da duração do trabalho no Título reservado às "normas especiais de tutela de trabalho", estabelecendo, inclusive, reduções de jornadas exatamente pelo fato de o trabalho ser prestado em condições que colocam em risco a saúde do trabalhador (artigos 227 e 253, por exemplo). Em suma, normas sobre duração do trabalho são consideradas, pela CLT, como normas destinadas à tutela especial do trabalho, o que reforça a sua natureza de norma de ordem pública. Aliás, a falta de compromisso com a realidade é uma constante na reforma, como decorre do artigo 477-A por ela acrescentado à CLT, que equipara, "para todos os fins", as dispensas imotivadas individuais às coletivas, como se os efeitos sociais de uma e outra fossem os mesmos. (Lei n. 13.467, 2017, on line).

15 Sob este prisma, o que se conclui, portanto, é que o capital controlou a política e fez com que fossem adotadas medidas de reforço do seu poder e, ao mesmo tempo, de fragilização dos poderes e contrapoderes que a ele poderiam ser contrapostos, visando a perpetuação do seu poder, o que torna a reforma trabalhista uma reforma essencialmente política.

16 A reforma trabalhista, ao adotar, no Direito Processual do Trabalho, a sucumbência recíproca em relação aos honorários, o faz exatamente na perspectiva de que o trabalhador pode recuar na pretensão de demandar contra o seu empregador diante da possibilidade de, ainda que vencedor em parte de suas demandas, ter que arcar com os custos dos honorários da parte contrária, ou 
seja, da possibilidade de o ajuizamento da demanda ser, ainda que em tese, economicamente injustificado. Com isto, direitos não respeitados não serão efetivamente exercidos.

17 A redução dos trabalhadores à condição de empresa constitui resultado da lógica segunda a qual "a auto exploração é muito mais eficiente que a exploração estranha, pois caminha de mãos dadas com o sentimento de liberdade [...]. Aqui não entra o outro como explorador, que me obriga a trabalhar e me explora. Ao contrário, eu próprio exploro a mim mesmo de boa vontade na fé de que possa me realizar" (HAN, 2017, p. 115-116), o que tem implicações também políticas, na medida em que "nesse contexto não é possível haver nenhuma resistência, levante ou revolução" (HAN, 2017, p. 116). Neste processo, entram em cena, ainda, as estratégias voltadas a reduzir a sociedade a um aglomerado de pessoas apáticas, passivas e indiferentes aos outros e ao bem comum, dentre as quais o culto ao individualismo, consumo, entretenimento e sexo.

18 Tal fato demonstra que o neoliberalismo não impõe apenas a política do livre comércio, mas traduz um modelo social, jurídico, econômico, político e cultural, informado pela concepção segundo a qual a essência da democracia é a livre busca individual do lucro, sendo o lucro e o fracasso resultados do mérito individual de cada um, o que desemboca na liberação do capital de qualquer responsabilidade social e em verdadeiro darwinismo social e até mesmo em darwinismo normativo, posto que o Estado, para concorrer com outros Estados, utiliza a redução dos custos da mão de obra e da proteção social como verdadeira mercadoria colocada no mercado mundial.

\section{REFERÊNCIAS}

ALMEIDA, Cleber Lúcio de. ALMEIDA, Wânia Guimarães Rabêllo de. Direito do Trabalho e Constituição: a constitucionalização do Direito do Trabalho no Brasil. São Paulo: LTr, 2017.

BAUMAN, Zygmunt. Danos colaterais: desigualdades sociais numa sociedade global. Rio de Janeiro: Zahar, 2013.

BAYLOS, Antonio. DEMOCRACIA POLÍTICA Y SISTEMA SINDICAL, reflexiones sobre la autonomía del sindicato. In: Sindicatos y cambios económicos y sociales. Wilfredo Sanguineti Raymond, Agustín García Laso (Coord.), 2002, p. 15-24. https://dialnet.unirioja.es/servlet/articulo?codigo=611583. Acesso em 15.05.18.

BECK, Ulrich. Liberdade ou capitalismo: Ulrich Beck conversa com Johannes Willms. São Paulo: UNESP, 2003.

BOBBIO, Norberto. 0 futuro da democracia: uma defesa das regras do jogo. 6 ed. Rio de Janeiro: Paz e Terra, 1986.

BRASIL. Conselho Nacional de Justiça. Justiça em número 2017, ano-base 2016. Disponível em: http://www.cnj.jus.br/files/conteudo/arquivo/2017/12/ b60a659e5d5cb79337945c1dd137496c. Acesso em: 
BRASIL. Lei n. 13.467, de 13 de julho de 2017. http://www.planalto.gov.br/ ccivil_03/_ato2015-2018/2017/lei/l13467.htm Acesso 04.08.2017.

BRASIL. Programa de Governo "Uma ponte para o futuro". Disponível em: https://www.fundacaoulysses.org.br/wp-content/uploads/2016/11/UMAPONTE-PARA-O-FUTURO.pdf Acesso em: 04.04.2017.

CASTEL, Robert. A discriminação negativa: cidadãos ou autóctones? Petrópolis: Vozes, 2011.

DARDOT, Pierre; LAVAL, Christian. A nova razão do mundo: ensaio sobre a sociedade neoliberal. São Paulo: Boitempo, 2016.

FERRAJOLI, Luigi. Poderes selvagens. São Paulo: Saraiva, 2014.

FERREIRA, António Casimiro. Para uma concepção decente e democrática do trabalho e dos seus direitos: (re)pensar o direito das relações laborais. In: A globalização e as ciências sociais. SANTOS, Boaventura de Sousa (org.). São Paulo: Cortez, 2002, p.257-297).

FERREIRA, António Casimiro. Política e sociedade: teoria social em tempo de austeridade. Porto: Vida económica, 2014.

FLORES, Joaquín Herrera: La complejidad de los derechos humanos. Bases teóricas para una definición crítica. Jura Gentium Rivista di filosofia del diritto internazionale e della politica globale, 2006. Disponível em: https:// www.juragentium.org/topics/rights/es/herrera.htm. Acesso em 29/04/2016.

GAMONAL, Sergio. "Derecho laboral, economía y pseudociencia”. In Derecho y Crítica Social 3(1) 1-44, 2017.

HAN, Byung-Chul. Sociedade do cansaço. 2 ed. Petrópolis: Vozes, 2017.

HOBBES, Thomas. Do cidadão. São Paulo: Martins Fontes, 1992.

MARTIN, Hans-Peter; SCHUMANN, Harald. A armadilha da globalização: o assalto à democracia e ao bem-estar social. São Paulo: Globo, 1998.

MARTÍNEZ, Gregorio Peces-Barba. Los derechos económicos, sociales y culturales: su génesis y su concepto. Derechos y liberdades - Revista del Instituto Bartolomé De Las Casas, n. 6, ano III (1998), p. 15-34. Disponível em http:hdl.handle.net/10016/1318. Acesso em 02.02.18. 
MAURER, Béatrice. Notas sobre o respeito à dignidade da pessoa humana ... ou pequena fuga incompleta em torno de um tema central. In: Dimensões da dignidade: ensaios de filosofia do direito e de direito constitucional. SARLET, Ingo Wolfgang (Org.). Porto Alegre: Livraria do Advogado, 2005.

NUNES, António José Avelãs. 0 Estado capitalista e as suas máscaras. Rio de Janeiro, Lumen Juris, 2013.

ONU. Agenda 2030 para o desenvolvimento sustentável. Disponível em: http://www.agenda2030.com.br/ Acesso em: 29.06.2016.

PISARELLO, Gerardo. La renta básica como derecho e como contrapoder. El vuelo de Ícaro, 2-3, 2001-2002, p. 91-108.

POSTONE, Moishe. Tempo, trabalho e dominação social. São Paulo: Boitempo, 2014.

RANCIÈRE, Jacques. 0 ódio à democracia. São Paulo: Boitempo, 2014.

ROMITA, Arion Sayão. Globalização da economia e Direito do Trabalho. São Paulo: LTr, 1997.

SANTOS, Boaventura de Sousa. Subjetividade, cidadania e emancipação. Revista de Ciências Sociais, n. 32, junho de 1991, p. 135-191.

SANTOS, Boaventura de Sousa. Reinventar a democracia. 2. ed. Lisboa: Gradiva, 2002.

SANTOS, Boaventura de Sousa. Esquerdas do mundo, uni-vos! São Paulo: Boitempo, 2018.

SCHNAPPER, Dominique. Contra o fim do trabalho. Lisboa: Terramar, 1998.

THATCHER. Margaret. Entrevista para o Sunday Times, em 03.05.81. Disponível em: https://www.margaretthatcher.org/document/104475 Acesso em: 29.05.2016.

TOURAINE, Alain. O que é a democracia? Petrópolis: Vozes, 1996.

Recebido em: 4-6-2018

Aprovado em: 3-11-2020 


\section{Cleber Lucio Almeida}

Pós-doutor em Direito pela Universidad Nacional de Córdoba. Doutor em Direito pela Universidade Federal de Minas Gerais. Mestre em Direito pela Pontifícia Universidade Católica de São Paulo. Professor dos cursos de graduação e pós-graduação (mestrado e doutorado) da Pontifícia Universidade Católica de Minas Gerais. Juiz do Trabalho junto ao TRT da 3 a Região. E-mail: cleberlucio@uai.com.br

\section{Wânia Guimarães Rabêllo Almeida}

Pós-doutora em Direito pela Universidad Nacional de Córdoba Doutora e mestra em Direito Privado pela PUC-Minas. Professora da Faculdade de Direito Milton Campos. Advogada. E-mail: waniag@uai.com.br

Pontifícia Universidade Católica de Minas Gerais

Prédio 05, R. Dom José Gaspar, 500 - Coração Eucarístico, MG, 30140-100 